\title{
Participation in Faculty-Led Off-Campus Programs as a Professional Devel- opment Opportunity for Early-Career Faculty
}

\section{Prof. Richard F. Vaz, Worcester Polytechnic Institute}

Richard F. Vaz received the PhD in electrical engineering from Worcester Polytechnic Institute (WPI), specializing in signal analysis and machine vision. He held systems and design engineering positions with the Raytheon Company, GenRad Inc., and the MITRE Corporation before joining the WPI Electrical and Computer Engineering faculty in 1987.

Rick is currently Dean of Interdisciplinary and Global Studies at WPI, with oversight of an academic unit focused on local and regional sustainability in support of WPI's interdisciplinary degree requirement, the Interactive Qualifying Project. Rick also oversees WPI's Global Perspective Program, a worldwide network of 35 Project Centers to which more than 700 students per year travel to address problems for local agencies and organizations under faculty supervision.

Rick's teaching and research interests include service and experiential learning, engineering design and appropriate technology, and internationalizing engineering education. He has developed and advised hundreds of student research projects in the Americas, Africa, Australia, Asia, and Europe. Rick has published over 55 peer-reviewed or invited papers and is the recipient of numerous teaching and advising awards including the WPI Trustees' Awards for Outstanding Teaching and for Outstanding Advising. From 2004 to 2010 he served as a Senior Science Fellow of the Association of American Colleges and Universities.

\section{Dr. Scott Jiusto, Worcester Polytechnic Institute}

Scott Jiusto is Associate Professor of Geography in WPI's Interdisciplinary and Global Studies Division and Director of the WPI Cape Town Project Centre. As regards this article, he has developed intensive, project-based experiential learning programs and mentored students both domestically and abroad. The Cape Town Project Centre engages students and faculty advisors in collaborative efforts with local governmental agencies and civic organizations to advance sustainable community development, especially in South Africa's informal settlements. Jiusto regularly prepares students to research and manage projects, develop proposals, presentations and reports, and engage in intercultural exchange, and has traveled with and advised students in Africa, Latin America, Europe, and the US. In Worcester, he works often with student project teams to advance campus and community sustainability, particularly in areas of energy and climate, and sustainability policy, assessment and communications. He also contributes to WPI professional development programming for faculty engaged in project advising. 


\title{
Participation in Faculty-Led Off-Campus Programs as a Professional Development Opportunity for Early-Career Faculty
}

\begin{abstract}
Since 1974, Worcester Polytechnic Institute (WPI) has operated a global network of off-campus programs where students complete degree-required, interdisciplinary research projects under faculty supervision. Each year about $10 \%$ of WPI's full-time faculty members spend a twomonth academic term off campus supervising student projects in locations throughout Africa, the Americas, Australasia, and Europe. Off-campus project advisors work closely with student teams, guiding their research and writing, and also assuming many non-academic roles. This paper describes results from a study of WPI tenure-track faculty who led student groups off campus during the probationary period prior to their tenure decision. Findings suggest that despite considerable demands of these assignments, early-career faculty experienced a variety of professional development benefits from their participation, including benefits to research and scholarly activity. Faculty who participated in off-campus advising prior to tenure received tenure at a higher rate than the campus average.
\end{abstract}

\section{Background}

Faculty-led experiential programs are an increasingly popular educational strategy, particularly for providing international experiences to STEM students ${ }^{1}$. Involvement in such programs requires faculty to assume new roles and responsibilities, some of which are non-academic ${ }^{2}$. Given the institutional value of faculty time, institutions considering such programs would benefit from knowing about the impact of these experiences on faculty careers in terms of professional development and, for probationary faculty, progress toward tenure.

Since 1974, Worcester Polytechnic Institute has operated off-campus project centers where students complete a general education requirement called the Interactive Qualifying Project (IQP), an interdisciplinary research project with a strong social component. Students at these centers, most of them STEM majors, work in small teams under faculty guidance for one of WPI's 7-week undergraduate terms to tackle problems posed by local organizations. Currently, 20 centers are located throughout Africa, the Americas, Asia/Pacific, and Europe. Off-campus IQPs have become a signature program of the university, with over $60 \%$ of undergraduate students participating in recent years.

Faculty members from all academic departments are invited to apply for these off-campus advising assignments. Typically, two advisors from different disciplines work with a cohort of 24-28 students completing six or seven interdisciplinary projects, typically with experienced advisors mentoring newer colleagues. WPI operates on a four-term undergraduate schedule, and project advising includes a seven-week on-campus preparation term followed by a seven-week travel term during which students work on their projects fulltime. In all, students earn credit equivalent to four and a half courses. Faculty advisors devote about 10 hours per week during the preparation term; during the travel term, advising is a fulltime responsibility. 
Faculty members who are interested in an off-campus assignment are asked to get their department head's approval before applying; departments are provided with resources to cover the faculty member's normal teaching assignment for that term. Over 30 advisors are needed to staff the program annually, and about $10 \%$ of WPI's full-time faculty members spend a term advising projects off campus each year, usually overseas. Off-campus project advisors work closely with student teams on matters such as research and writing strategies, navigating team dynamics challenges, working in professional settings, and cross-cultural engagement. Advisors also assume important non-academic roles, including attending to health, safety, and risk management issues, housing and transportation logistics, and support for students experiencing emotional and/or behavioral difficulties. To prepare faculty for these challenges and support them during the off-campus sojourn, WPI uses a strategy combining mentoring, training, on-line resources, and support networks ${ }^{3,4}$.

Given the importance of how faculty members spend their time, it is worth asking how offcampus advising impacts professional development and career success. This question is of special significance for early-career faculty who are trying to earn tenure at institutions like WPI, where research and scholarship are important factors in tenure, promotion, and faculty evaluation. Understandably, some faculty and administrators harbor reservations regarding the professional merits of off-campus assignments, particularly for probationary (pre-tenure) faculty. The goal of this study was to explore the experiences of probationary faculty who participated in off-campus project advising, particularly in terms of professional development and progress toward tenure.

\section{Methodology}

This study, which covers 16 years of program activity, involved two surveys of faculty who had advised off-campus projects during the probationary periods of their tenure-track appointments, plus analysis of data regarding tenure success. The survey, administered in 2006 and again in 2011, consisted of open-ended questions regarding advisor attitudes toward the assignment, their perceptions of the attitudes of others, the professional and personal impacts they perceived, and whether or not they would recommend such an assignment to a colleague prior to tenure. The survey was sent to all 24 faculty who qualified for the study at the times it was administered.

Overall, 16 of 24 advisors surveyed responded, a $67 \%$ response rate for the two surveys combined. Content analysis was used to identify recurring themes, and representative comments were extracted to illustrate recurring viewpoints. In 2013, tenure success data were compiled for all 24 faculty and compared to campus wide data. There are numerous limitations to this study. Since participation in the program requires approval from each faculty member's department head, participants may be likely to have made good progress toward tenure at that point in their careers, and were almost certainly favorably predisposed toward the off-campus project program. The survey was not administered anonymously, so participant responses may have been influenced by social desirability bias, and nonresponse bias is possible as well. No statistical inferences are made.

\section{Findings}


In this section, primary findings of the study will be described.

- Relatively few probationary faculty advised off-campus projects: over 16 years, 24 probationary faculty members participated. This represents about $10 \%$ of probationary faculty during that period.

- Faculty who advised off-campus projects before tenure secured tenure at a higher rate than the campus average during a similar timeframe. The faculty in the study participated in the program between 1995 and 2011. The available campus average was from 2000 to 2011.

- Department Heads varied with respect to support for probationary faculty advising offcampus: some were opposed, some cautiously supportive when tenure progress was strongly evidenced and/or advising brought clear scholarly development opportunities, and others were very supportive unless tenure progress was questionable. Interestingly, several faculty members described strong discouragement from their Department Heads, and yet chose to participate in the program.

- Off-campus project advising was described as challenging and time-consuming: respondents indicated that advising was an engrossing, demanding experience. A few mentioned that research activities were limited due to advising commitments; others found time away from other campus commitments promoted scholarship. One said, "Honestly, it is just as hard to get research done when I'm teaching my large 50-55 person class with no TA."

- Participants were overwhelmingly positive about their advising experience, with 15 of $16(94 \%)$ describing strong personal and professional benefits, while 1 respondent found time demands during preparation unexpectedly and undesirably demanding. About half of the participants indicated they would advise a colleague to advise off campus prior to tenure; the other half indicated that "it depends" on factors such as based on progress toward tenure.

- Off-campus project advisors described a wide range of benefits to teaching and advising, research, and the institution, as illustrated by the following quotes.

○ Understanding students: "I really learned a great deal about [student] abilities...I was able to connect with the students on a level which I had not experienced in any other teaching at WPI - even grad advising in my lab; because of getting to know students overseas, I am much better as an advisor back in Worcester. I am a better teacher, too."

○ On-campus project advising: "What I learned gave me a lot more tools for being an effective project advisor; I learned so much about how I SHOULD be advising my project-based work, that I was/am embarrassed about my on-campus advising; helped me in developing appropriate projects for on-campus students; I also gained in my ability to advise students (undergrads and grads) in ...writing reports and manuscripts."

- Networking, research, and funding opportunities: [Off-campus advising] "opens up new research and other professional opportunities... I met with researchers in my field who were at local universities, and gave informal presentations of my work; It allows me to contemplate research projects that are global and comparative in nature, instead of very narrowly focused on countries I already knew. In fact, my research agenda for the next few years grows out of this--and would not have been possible without my off-campus advising experiences. The grant I have in with NSF now grew directly out of the places I have been with WPI students."

- Strengthened scholarship and graduate advising: [Advising has] "made me a better writer; made me more conscious of research methods; I am better able to advise grad 
students in writing journal papers; a better advisor on every level (undergrad and grad)."

- Job satisfaction: "It affected me profoundly...It has been a wonderful experience ...It's one of the best parts of my job... the most rewarding teaching-learning experience that I had enjoyed up to that time at WPI; I'm not sure I would have stayed at WPI as long without the opportunity to teach overseas. I've also gotten to know faculty from other departments very well by doing overseas projects."

- Institutional collaboration: "I enjoyed co-advising with a colleague from a very different discipline than my own. Much of what I learned from [a co-advisor] I am now applying to on-campus projects... It certainly has helped me understand the institution better, and I can only imagine this unique interaction contributes to the generally healthy faculty environment at WPI, where a measure of respect and acceptance seems to be the norm across campus."

- Faculty recruitment and retention: "These opportunities are clearly a professional opportunity offered to me that are not available at any other school."

\section{Discussion}

Given the positive reaction of participants in this study to their off-campus advising experiences and their success in earning tenure, it seems clear that these experiences were beneficial - or at least, not detrimental - to the career success and advancement of the participating faculty. That said, it is important to note that the participants were self-selected and had gained approval of their department heads for the assignments. Thus, there is no basis to conclude that such assignments would be beneficial to faculty with different interests or in different situations. Evidence does suggest, however, that faculty members are discerning in deciding whether to participate in these programs, and that those who do participate report professional and personal benefits far outweighing any detriments.

The majority of professional development benefits reported by participants pertain to working with students, as might be expected from an intensive teaching experience. However, it is interesting to note the breadth of benefits that go beyond strengthening undergraduate teaching abilities. In particular, faculty descriptions of benefits to their research programs, guidance of graduate students, and professional networks may be of interest to administrators looking to help newer faculty successfully develop both as effective educators and productive scholars. For example, several respondents took advantage of their temporary assignment to develop research collaborations, give talks about their work, and visit prospective funders. Others found ways to apply improved student advising skills to their work with graduate research students.

Two participants reported that working with a co-advisor from a different discipline had helped them become better writers themselves; typically, advisors from STEM disciplines are paired with a co-advisor whose expertise is in social sciences, humanities, or business. There was also evidence that off-campus advising assignments can engender institutional loyalty, promote diffusion of "best practices" for working with students, and build a sense of community and shared mission through cross-fertilization of ideas and perspectives. Indeed, it has been WPI's experience that faculty take pride in their advising participation, perhaps because off-campus projects are seen as a signature program for the university. 
While the level of faculty involvement in off-campus and international experiential education at WPI is unusually high, increasing interest in high-impact practices and global learning are leading to these types of faculty-led activities becoming more common at different types of institutions. Research universities, in particular, will have to make careful judgments involving faculty participation in off-campus experiential programs. While more study of the impacts of nontraditional teaching assignments on faculty are warranted, the experience at WPI suggests that such assignments can be beneficial both for participating faculty and the university, providing opportunities for helping faculty become more effective teachers, advisors, mentors, and scholars.

\section{References}

1. Donnelly-Smith, L., "Global Learning through Short-Term Study Abroad," Peer Review, Association of American Colleges and Universities, Fall 2009.

2. Barnhart, B., T. Ricks and P. Spier, "Faculty Roles," NAFSA's Guide to Education Abroad for Advisers and Administrators, Hoffa and Pearson eds., $2^{\text {nd }}$ Edition, 1997.

3. Mello, N.A., "Preparing Faculty for a Global Experience," Proceedings of the $35^{\text {th }}$ ASEE/IEEE Frontiers in Education Conference, October 2005.

4. Vaz, R., and C. Demetry, "Recruitment, Mentoring, and Development of STEM Faculty to Lead International Programs," Proceedings of the 40 ASEE/IEEE Frontiers in Education Conference, October 2010. 